\title{
Franciscana bycatch is not reduced by acoustically reflective or physically stiffened gillnets
}

\author{
P. Bordino ${ }^{1, *}$, A. I. Mackay ${ }^{2}$, T. B. Werner ${ }^{3,4}$, S. P. Northridge ${ }^{2}$, A. J. $\operatorname{Read}^{5}$ \\ ${ }^{1}$ Fundación AquaMarina-CECIM, Del Besugo 1525, Pinamar (7167) Buenos Aires, Argentina \\ ${ }^{2}$ Sea Mammal Research Unit, School of Biology, University of St Andrews, Fife, KY16 9TS, UK \\ ${ }^{3}$ Boston University Marine Program, 5 Cummington Street, Boston, Massachusetts 02215, USA \\ ${ }^{4}$ Marine Conservation Engineering Program, New England Aquarium, Boston, Massachusetts 02110-3399, USA \\ ${ }^{5}$ Division of Marine Science and Conservation, Nicholas School of the Environment, Duke University, Beaufort, \\ North Carolina 28516, USA
}

\begin{abstract}
The incidental capture of franciscana Pontoporia blainvillei in gillnet fisheries of Argentina, Uruguay and Brazil represents a major conservation threat to this species. We report on an experimental trial that compared franciscana bycatch rates in standard gillnets to gillnets with 1 of 2 modifications: increased acoustic reflectivity by infusion of barium sulphate $\left(\mathrm{BaSO}_{4}\right)$ or increased flexural stiffness of the nylon twine. Field trials were conducted in association with artisanal fishermen at San Clemente del Tuyu in Bahia Samborombon, Argentina, between October 2009 and March 2010. Depth sensors were used to record the underwater fishing behaviour of the 3 net types. Seventy-seven dolphins were observed incidentally captured in 807 monitored gillnet hauls, with similar fishing effort observed for each net type. There was no significant difference in franciscana bycatch rates $(p>0.05)$ or target fish catches $(p>0.05)$ among the 3 net types. The stiff net twine had a slightly but significantly higher flexural stiffness (FS) than the reflective or control net twine. The FS of the dry stiff twine was similar to that previously reported for $\mathrm{BaSO}_{4}$ twine with a similar diameter; in contrast, the FS of the reflective nylon was, unexpectedly, much lower. However, the difference in the FS between wet, submerged stiff twine and control twine used in the field was estimated at $19.4 \%$. The $\mathrm{BaSO}_{4}$ net fished with a significantly lower mean float line height than either the control or stiffened net. These results show that the use of reflective or stiff nets does not lead to a reduction in franciscana bycatch rates; therefore, other management strategies need to be developed to reduce the impact of incidental captures of this species.
\end{abstract}

KEY WORDS: Bycatch · Gillnet · Franciscana $\cdot$ Artisanal fishery

\section{INTRODUCTION}

Incidental capture, or bycatch, in fisheries is a conservation concern for many populations of long-lived megafauna such as marine mammals, elasmobranchs, sea turtles and seabirds (Goldsworthy \& Page 2007, Read 2008, Gilman et al. 2010, Anderson et al. 2011). The bulk of global cetacean bycatch is believed to occur in gillnets (Read et al. 2006), one of the most im- portant fishing gears used worldwide (He 2006). Gillnets are widely used in small-scale fisheries as they are relatively inexpensive, require little infrastructure (e.g. bait or sophisticated electronics) and can be deployed and retrieved easily from small boats.

Franciscana Pontoporia blainvillei are taken as bycatch in coastal gillnets throughout their limited range (Praderi et al. 1989, Corcueara et al. 1994, Bordino et al. 2002, Secchi et al. 2003). As a result, the 
species is listed as Vulnerable by the IUCN (Reeves et al. 2008) and is considered to be the most threatened cetacean in the Southwest Atlantic (Secchi 2010). In coastal waters of Buenos Aires Province, Argentina, an estimated 650 dolphins are bycaught annually (Bordino \& Albareda 2004). The most recent population estimate for this species in Argentinean waters is 14000 individuals (Crespo et al. 2010), so it is unlikely that current bycatch levels are sustainable, and management measures are, therefore, urgently required to reduce the incidental bycatch of the species.

The use of acoustic alarms has been shown to significantly reduce the bycatch rates of franciscana (Bordino et al. 2002) and other cetaceans in gillnets (Kraus et al. 1997, Carretta et al. 2008), but the financial cost of implementation and enforcement of pinger use limits their applicability in many smallscale fisheries (Read 2008). Concerns that the widespread use of acoustic alarms could result in habituation or habitat exclusion remain (Dawson et al. 2013, this Theme Section), although long-term deployment of acoustic alarms in several commercial fisheries has not resulted in an increase in cetacean bycatch rates in properly equipped nets (Palka et al. 2008, Carretta \& Barlow 2011). Time-area closures have also been used to reduce cetacean bycatch in gillnet fisheries (Slooten 2013, this Theme Section), but also require a specific set of circumstances to be successful, are often unpopular with fishery participants and are expensive to enforce. The specific set of circumstances needed for their effective implementation include that the temporal and spatial patterns of bycatch are predictable, closures effect only a small subset of the total fishing grounds, displacement of fishing effort to other areas does not result in higher overall bycatch rates and fishermen are willing to cooperate for successful enforcement (Murray et al. 2000). When a high overlap between the distribution of the species and the fishery effort exists, time-area closures can be economically unsustainable. Due to the social and economic framework of the artisanal gillnet fishery in San Clemente del Tuyu, time-area closures are not considered a viable mitigation method for this fishery.

In contrast, modifications to fishing gear can provide a relatively low-cost method of reducing the incidental capture of non-target species, requiring a one-time expenditure on new gear (Watson et al. 2005, Campbell et al. 2008). To date, however, there have been only a limited number of trials of gillnet modifications that have demonstrated a significant decrease in cetacean bycatch.
The mechanism(s) by which cetaceans become entangled in gillnets are not well understood, but one hypothesis is that animals are unable to detect gillnets at sufficient distance to avoid them. Several studies have aimed to reduce cetacean bycatch in gillnets by increasing the acoustic reflectivity of the nets (Dawson 1994, Northridge et al. 2003, Trippel et al. 2003, 2009, Larsen et al. 2007), most recently by the addition of materials such as barium sulphate $\left(\mathrm{BaSO}_{4}\right)$ or iron oxide $(\mathrm{FeO})$ to increase the target strength of the nylon mesh of the gillnet webbing.

To date, 2 trials have shown a significant reduction in harbour porpoise Phocoena phocoena bycatch rates in 'acoustically reflective' gillnets (Larsen et al. 2007, Trippel et al. 2009), but a third trial found no such reduction (Northridge et al. 2003). The results obtained by Larsen et al. (2007) and Trippel et al. (2009) appear promising, but the mechanism by which bycatch was reduced in these studies remains unclear.

The $\mathrm{BaSO}_{4}$ impregnated nylon gillnets nets tested by Trippel et al. (2009) had a greater target strength (TS) than equivalent standard nylon gillnets (Mooney et al. 2007), but this difference only occurred at or near perpendicular angles of incidence to the net. Larsen et al. (2007) found no significant difference in the TS of FeO-impregnated nylon and standard gillnets at an angle of incidence of $0^{\circ}$, when the sound signal is transmitted perpendicular to the face of the net.

An artefact of adding $\mathrm{BaSO}_{4}$ or FeO to nylon is an increase in the flexural stiffness (FS) of the twine (Larsen et al. 2007, Mooney et al. 2007). A number of authors have, therefore, postulated that the observed reduction in harbour porpoise bycatch in the studies by Larsen et al. (2007) and Trippel et al. (2009) could be due, in whole or part, to this increased stiffness (Larsen et al. 2002, Cox \& Read 2004, Mooney et al. 2004, 2007, Trippel et al. 2009). Increasing the stiffness of a gillnet is an attractive potential mitigation strategy due to the relatively low cost of such a modification, assuming of course that target species catch rates would not be reduced significantly as a result. The objective of the current experimental trial, therefore, was to determine whether bycatch rates of franciscana in a smallscale gillnet fishery in San Clemente del Tuyu, Argentina, could be reduced by increasing the acoustic reflectivity or only the stiffness of gillnets. The trial consisted of a controlled comparison of both fish catch and franciscana bycatch rates in acoustically reflective and stiffened gillnets with control nets typically used in this fishery. 


\section{MATERIALS AND METHODS}

\section{Net characteristics}

The monofilament nylon material used to construct the webbing of the 3 gillnets (control, reflective, stiff) was specifically produced for the field trial by a manufacturer in China. The 3 twine types were specified to have a diameter of $0.57 \mathrm{~mm}$. The target concentration of $\mathrm{BaSO}_{4}$ by weight in the reflective net monofilament was $10 \%$, and stiffness of the stiff nylon twine was produced by adding a different grade of nylon. It was expected that the reflective and stiff nylon would have equal, but greater, FS than the control nylon, and that the reflective nylon would have a higher TS than either the control or stiff nylon. Prior to the commencement of the field trial the average $\mathrm{BaSO}_{4}$ content in the reflective nylon (measured from 3 samples) was $9.8 \%( \pm 0.1 \mathrm{SD})$, and $9.6 \%( \pm 0.5 \mathrm{SD})$ after the nets had been fished for 1 mo.

The FS of each monofilament nylon twine type was measured following the methodology described by Mooney et al. (2007). Thirty samples of twine, each 30 $\mathrm{cm}$ in length, were taken from the first factory production run of each of the 3 nylon types (control, reflective, stiff). The diameters of these monofilaments $(0.625,0.6$ and $0.6 \mathrm{~mm}$, respectively) were slightly different $(0.025$ to $0.05 \mathrm{~mm})$ from the monofilaments used in subsequent factory runs to produce the experimental nets (Table 1), but the material properties were identical. The ends of each strand were clamped to a metal arm so that the monofilament formed a loop extending downward. A pre-weighed cup was suspended from the bottom of the loop by a small hook, and mass was gradually added to the cup until the widest part of the loop measured $5 \mathrm{~mm}$. These results therefore produced a measure of FS for each of the nylon types when dry. Each strand was subsequently submerged in a small aquarium with circulating seawater for $48 \mathrm{~h}$, and then, after being

Table 1. Twine diameter of the 3 nylon types from the first factory samples produced for the experimental trial and for the twine samples actually used in the Argentinean gillnets. (The factory order for the Argentina samples was for \#12, $57 \mathrm{~mm}$; the differences reflect issues of quality control during manufacturing)

\begin{tabular}{|lcc|}
\hline Net type & $\begin{array}{c}\text { Factory samples } \\
(\mathrm{mm})\end{array}$ & $\begin{array}{c}\text { Argentina samples } \\
(\mathrm{mm})\end{array}$ \\
\hline Control & 0.625 & 0.575 \\
Reflective & 0.6 & 0.575 \\
Stiff & 0.6 & 0.625 \\
\hline
\end{tabular}

wiped dry, was retested using the same methodology. Monofilament diameter was confirmed using a dissecting microscope and a calibrated lens with a micrometer. Differences in FS between the 3 types of nylon were evaluated using a 1-way ANOVA.

\section{Fishing trials}

Experimental trials were conducted in a gillnet fishery operating at San Clemente del Tuyu in Bahia Samborombon, Buenos Aires Province, Argentina (Fig. 1). The fleet consists of 50 to 60 small (6 to $10 \mathrm{~m}$ in length) fibreglass launches, targeting primarily striped weakfish Cynoscion guatucupa and whitemouth croaker Micropogonias furnieri. Each net consisted of two $50 \mathrm{~m}$ panels of $140 \mathrm{~mm}$ stretched mesh nylon monofilament net, with a rigged height of $3.5 \mathrm{~m}$. All nets were rigged with equal amounts of flotation and lead line weight and were marked with a unique number code. The type of net was identifiable by a coloured buoy at either end. Three fishing boats took part in the experimental trial, with each boat deploying an equal number of strings of each net type per trip. Nets were set 100 to $300 \mathrm{~m}$ apart and set parallel or perpendicular to the current depending on the fishing location. Net spacing was arbitrary, but was chosen so that rates of fish and nontarget catches would be comparable, but given the length of the nets, the gear would be separated by a sufficient distance that each set could be considered

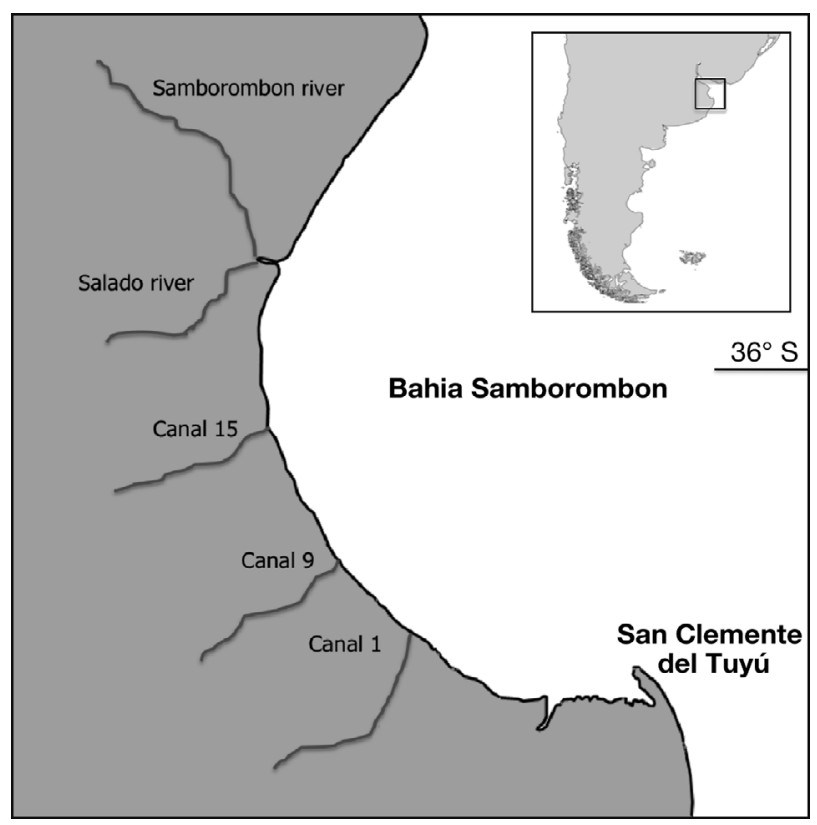

Fig. 1. Study area in Bahia Samborombon, Argentina 
independent. Nets were hauled by hand, with both the headline and lead line brought aboard the boat. As a result, the anchors at either end of a net were generally not hauled, so individual nets remained in the same location until all nets were moved to a different fishing area. At each haul, data on fishing activities were recorded by independent onboard observers. Recorded data included fishing locations, soak times, environmental conditions and dolphin bycatches. Drop outs, where an entangled animal falls out of the net unnoticed during haul back, can negatively bias bycatch rates (Vinther \& Larsen 2004). In the current study it is unlikely that drop outs would have occurred without being noticed by observers, given the relatively short length of the gillnets used and the fact that they were hand hauled. Total fish catches in each haul, estimated by weight, were recorded for whitemouth croaker, striped weakfish, king weakfish Macrodon ancylodon and 1 discarded species, Brazilian menhaden Brevoortia aurea. Lengths were also recorded for samples of whitemouth croaker and striped weakfish.

\section{Fishing behaviour of gillnets}

To compare the underwater fishing behaviour of the gillnets, a pair of depth temperature loggers (Star ODDi DST-milli; $\pm 0.4 \mathrm{~m}$ accuracy) were deployed on the float and lead lines of each control, reflective and stiff net during 3 subsequent fishing trips in August 2011. By placing sensors on both the float and lead lines, the active fishing height of the net can be calculated as the difference in depth measured between each pair of sensors, thereby negating the need to take fluctuations in tidal height into consideration. After calibration, sensors were assigned to pairs, which were rotated among the 3 net types. Depth was recorded at $10 \mathrm{~min}$ intervals, and active fishing heights of the 3 nets were compared using a generalised linear model (GLM) with Gamma error distribution and inverse link function. These data were also used to calculate the proportion of the theoretical net area fished by each net. The 2-dimensional theoretical fishing area of a gillnet can be calculated as the length of the net multiplied by the rigged height of the net.

\section{Data analysis}

Count data models, such as Poisson and quasi-Poisson, and negative binomial models are commonly used to analyse bycatch data. The simplest of these is the Poisson model, in which the variance of the uncertainty in the data is assumed to equal the relevant expected values. However, bycatch data are often over-dispersed relative to the Poisson (Minami et al. 2007, Gardner et al. 2008, Sims et al. 2008, Orphanides 2009), and therefore require models that relax this assumption. GLMs with Poisson, quasiPoisson and negative binomial error distributions were constructed, and their residual errors and dispersion estimates were tested for over-dispersion. The results indicated slight over-dispersion; thus, to be conservative, the negative binomial was used to investigate the effect of net type, location (latitude, longitude, distance from shore), depth and fish catches (for 3 target and 1 discard fish species) on dolphin bycatch, using stepwise forward and backward model selection. Data on whether nets were set parallel or perpendicular to the current were not recorded for all hauls and were therefore not included in the model. As depth data could not be collected onboard the fishing vessels, depths were estimated from bathymetry data and fishing locations grouped in depth bins of $\leq 5,6$ to 10 and 11 to $15 \mathrm{~m}$. The natural logarithm of soak time was included as an offset in all models so that dolphin bycatch was modeled as a rate. A generalised additive model (GAM) with negative binomial error distribution (theta $=3.7$ ) was used to investigate whether dolphin bycatch events were clumped through time, by looking for non-linear trends in the data.

The effect of net type on catch rates ( $\mathrm{kg} / \mathrm{soak}$ time) of the 3 target and 1 discard species were investigated using a GLM with negative binomial error distribution. A Kolmogorov-Smirnov test was used to compare length-frequency distributions (LFD) of a subset of fish (whitemouth croaker and striped weakfish) from the 3 net types. All data analyses were performed in the computer package R (V2.11.1).

\section{RESULTS}

\section{Flexural stiffness of nylon twine}

The mean FS of the control, reflective and stiff nylon were $169.4,152.0$ and $239.7 \mathrm{~g}$, respectively, for the dry samples, and 69, 63 and $75.6 \mathrm{~g}$, respectively, for the samples which had been immersed in seawater for $48 \mathrm{~h}$, hereafter termed 'wet' samples (Fig. 2). There were significant differences among the FS of the 3 twine types for both dry (1-way ANOVA; $\left.F_{2,87}=574.2, \mathrm{p}<0.001\right)$ and wet samples (1-way ANOVA $\left.; F_{2,87}=23.48, \mathrm{p}<0.001\right)$. Results of general 


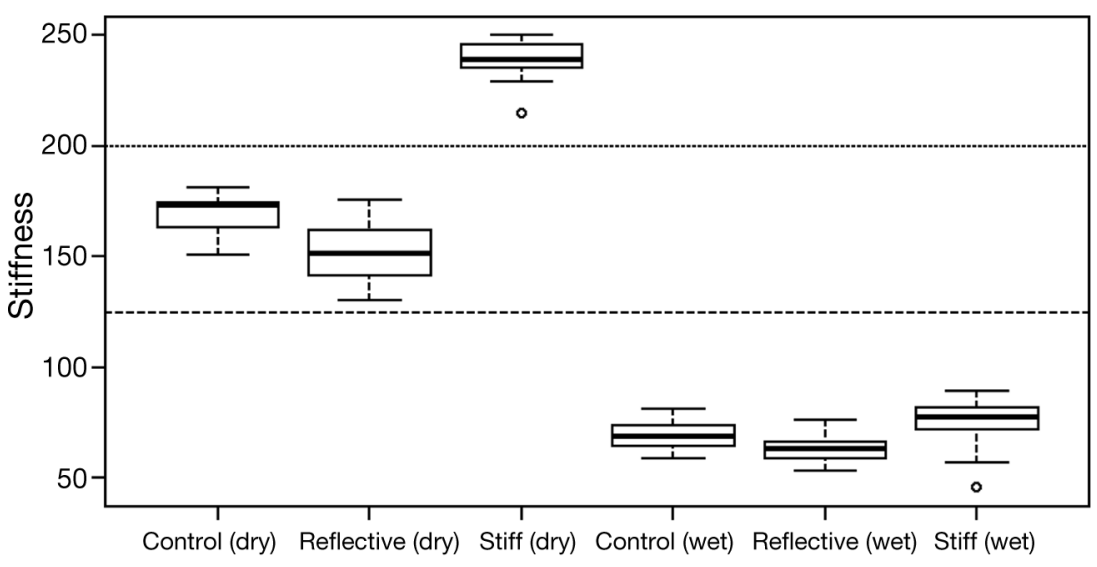

Fig. 2. Flexural stiffness of 3 nylon types (used as gillnet twine) for dry and wet samples (boxplot shows median, quartiles, 90th and 10th percentiles and outliers). Horizontal lines indicate stiffness measurements of the dry (dotted) and wet (dashed) $\mathrm{BaSO}_{4}$ line reported by Mooney et al. (2007)

linear hypothesis testing using Tukey's all pairwise comparisons showed the FS of the stiff nylon was significantly higher than that of both the control (dry: $\mathrm{p}<0.001$, wet: $\mathrm{p}<0.01$ ) and reflective nylon (dry: $\mathrm{p}<0.001$, wet: $\mathrm{p}<0.001$ ). The FS of the control nylon was also significantly higher than that of the reflective nylon (dry: $\mathrm{p}<0.001$, wet: $\mathrm{p}<0.01$ ). The FS of the stiff twine, for dry samples only, was similar to that previously reported for $\mathrm{BaSO}_{4}$ twine with a similar diameter (Mooney et al. 2007), but the FS of the reflective nylon was, unexpectedly, much lower. However, the nylon monofilament used to compare FS with the barium sulfate-infused monofilament in that previous study was not sourced from the same manufacturer (A. Mooney pers. comm.) and may have been produced using a different grade of nylon. As shown in our FS measurements, using different grades of nylon can result in stiffness differences between monofilaments. The present study used identical grades of nylon for both the standard and barium sulphate nets.

\section{Fishing trials}

A total of 807 gillnet hauls were observed during 157 fishing trips conducted between October 2009 and March 2010. Nets were deployed in 150 different locations, and each location was sampled between 1 and 19 times. Two main fishing grounds were utilised, an area inside Bahia Somborombon (BS) at water depths of 3 to $7 \mathrm{~m}$ and offshore of San Clemente del Tuyu (SC) at depths up to $17 \mathrm{~m}$ (Figs. 1 \& 3). Most (84\%) fishing effort was observed in $\mathrm{SC}$, which accounted for $94 \%$ of bycatch events. Mean $( \pm \mathrm{SD})$ fishing effort was similar for all 3 net types $\left(962.36 \pm 63.06 \mathrm{~km} \mathrm{net}^{-1}\right.$ $\mathrm{h}^{-1}$ ). Franciscana bycatch was recorded in $68 \mathrm{ob}-$ served hauls (Fig. 3b), resulting in a total bycatch of 77 dolphins. The number of dolphins caught per haul ranged between 1 and 3 individuals, but most $(88 \%)$ bycatch events consisted of a single animal. Approximately half $(58 \%)$ of the dolphins were males, and $66 \%$ of all animals were mature (based
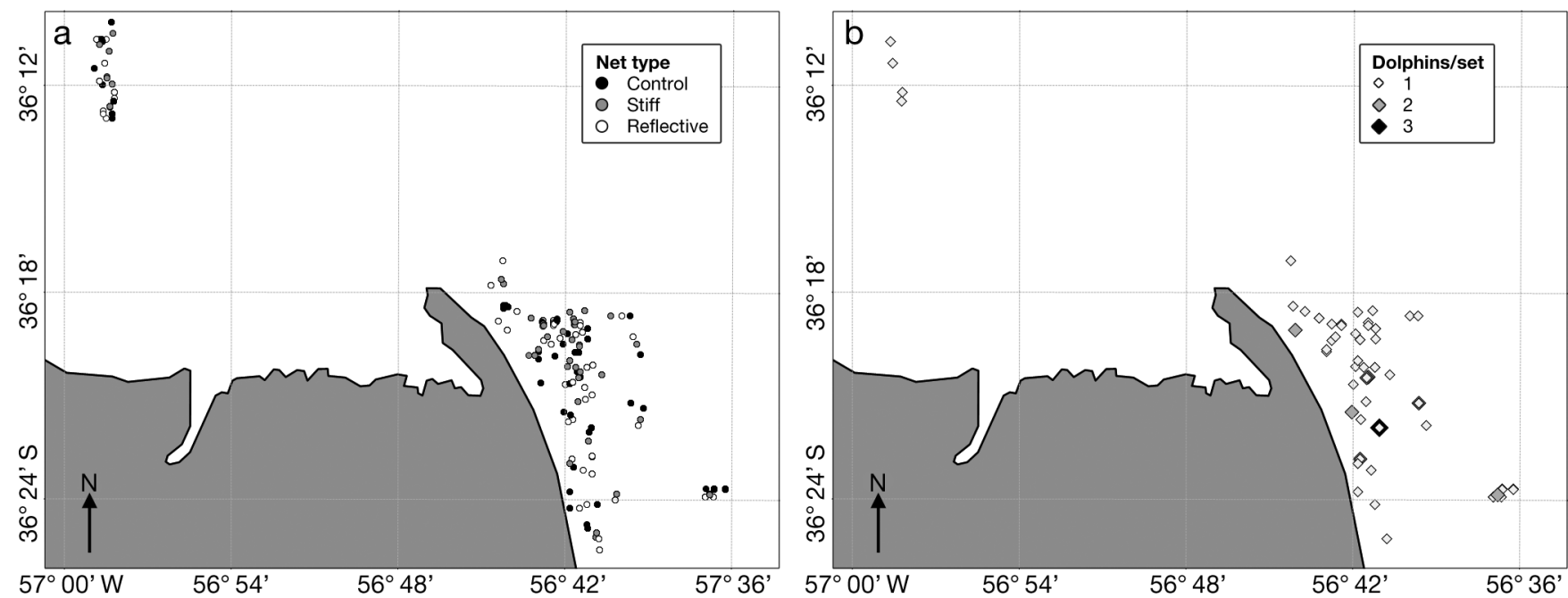

Fig. 3. (a) Locations of all observed hauls by net type in the 2 main fishing areas, Bahia Somborombon and San Clemente (Fig. 1). (b) Locations of all franciscana Pontoporia blainvillei bycatches as number of dolphins per haul 
on total body length; see Kasuya \& Brownell 1979). Data on observed fishing effort and dolphin bycatches (both as number of events and number of individuals) are summarised by net type in Table 2. There was no significant difference in the bycatch rate of franciscana among the control, reflective, or stiff nets ( $p>0.05)$.

Highest bycatch rates were recorded at depths of 11 to $15 \mathrm{~m}$; however, this explanatory variable was not retained in the best model, as judged by Akaike's information criterion (AIC), of the data. After model selection, the final negative binomial GLM retained the variables longitude, whitemouth croaker catch, and an interaction between these terms as the best predictors of dolphin bycatch, though none was statistically significant $(\mathrm{p}>$ 0.05). If longitude was excluded from step selection, the final model retained the variables depth and whitecroaker catch, with a positive significant relationship between bycatch rates and the depth category 10 to $15 \mathrm{~m} \mathrm{(p} \mathrm{<}$ 0.01) and with a negative significant relationship with whitecroaker catch ( $\mathrm{p}<0.05)$. However, this model had a higher AIC value than the best model when longitude was included (Table 3). No temporal explanatory variables were retained in the final model, and an investigation of bycatch rates through time using a GAM with negative binomial distribution showed a linear increase over time, but no evidence of temporal aggregation.

There were also no significant differences in CPUE for the 3 target fish species $(\mathrm{p}>0.05)$ or 1 discard species ( $p>0.05$ ) among the 3 net types (Fig. 4). The mean length of a subsample of fish caught in the 3 net types was similar for both striped weakfish and whitemouth croaker (Fig. 5a,b). There was no significant difference in the LFD of striped weakfish between the control and reflective (KolmogorowSmirnov (KS): $\mathrm{p}>0.1$ ) or control and stiff nets (KS: $\mathrm{p}>$ 0.1) (Fig. 5a,b). Likewise there was no significant difference in the LFD of whitemouth croaker between the control and reflective nets (KS: p > 0.05). How-
Table 2. Summary of observed fishing effort and franciscana Pontoporia blainvillei bycatch (number of events and individuals) and catch per unit effort (CPUE) by haul and kilometer net hour fished

\begin{tabular}{|lcccccc|}
\hline Net & Hauls & $\begin{array}{c}\text { Bycatch } \\
\text { events }\end{array}$ & $\begin{array}{c}\text { No. of } \\
\text { dolphins }\end{array}$ & $\begin{array}{c}\text { Fishing effort } \\
\left(\mathrm{km} \mathrm{net}^{-1} \mathrm{~h}^{-1}\right)\end{array}$ & $\begin{array}{c}\text { CPUE } \\
(\text { haul })\end{array}$ & $\begin{array}{c}\text { CPUE } \\
\left(\mathrm{km} \mathrm{net}^{-1} \mathrm{~h}^{-1}\right)\end{array}$ \\
\hline Standard & 279 & 22 & 27 & 1019.12 & 0.08 & 0.03 \\
Reflective & 255 & 25 & 27 & 894.48 & 0.10 & 0.03 \\
Stiff & 273 & 21 & 23 & 973.48 & 0.08 & 0.02 \\
Total & 807 & 68 & 77 & 2887.08 & & \\
\hline
\end{tabular}

Table 3. Summary of parameter estimates, standard errors (SE), p-values and Akaike's information criterion (AIC) for the best model and for the best model when longitude is excluded

\begin{tabular}{|lccc|}
\hline Best model parameters & Estimate & SE & p-value \\
\hline Best model including longitude & & & \\
Longitude & 0.371 & 2.9897 & 0.901 \\
Whitemouth croaker catch & 11.1491 & 8.2603 & 0.177 \\
Longitude: whitemouth & 0.1969 & 0.1457 & 0.177 \\
$\quad$ croaker catch & & & \\
AIC & 525.18 & & \\
Best model excluding longitude & & & \\
Depth (6-10 m) & 0.1243 & 0.2927 & $>0.05$ \\
Depth $(11-15$ m) & 0.8494 & 0.3114 & $<0.01$ \\
Whitemouth croaker catch & -0.0200 & 0.0100 & $<0.05$ \\
AIC & 527.31 & & \\
\hline
\end{tabular}

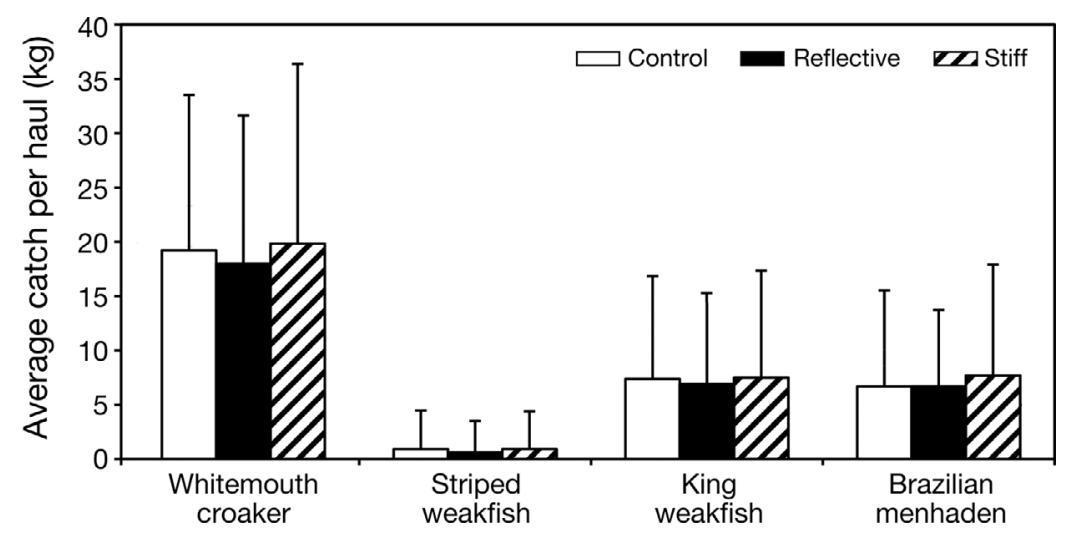

Fig. 4. Average fish catch per haul $(\mathrm{kg})$ of the 3 main target species (whitemouth croaker Micropogonias furnieri, striped weakfish Cynoscion guatucupa, king weakfish Macrodon ancylodon) and the bycatch species Brazilian menhaden Brevoortia aurea in control, reflective and stiff nets. Error bars are SD ever, a significant difference in the LFD of whitemouth croaker was found between the control and stiff nets (KS: $\mathrm{p}<0.05)$. A bimodal length distribution was seen in all nets for this species, but the dip in the distribution occurred around $51 \mathrm{~cm}$ length in the stiff net, compared to approximately $54 \mathrm{~cm}$ in the other 2 nets (Fig. 5a). 


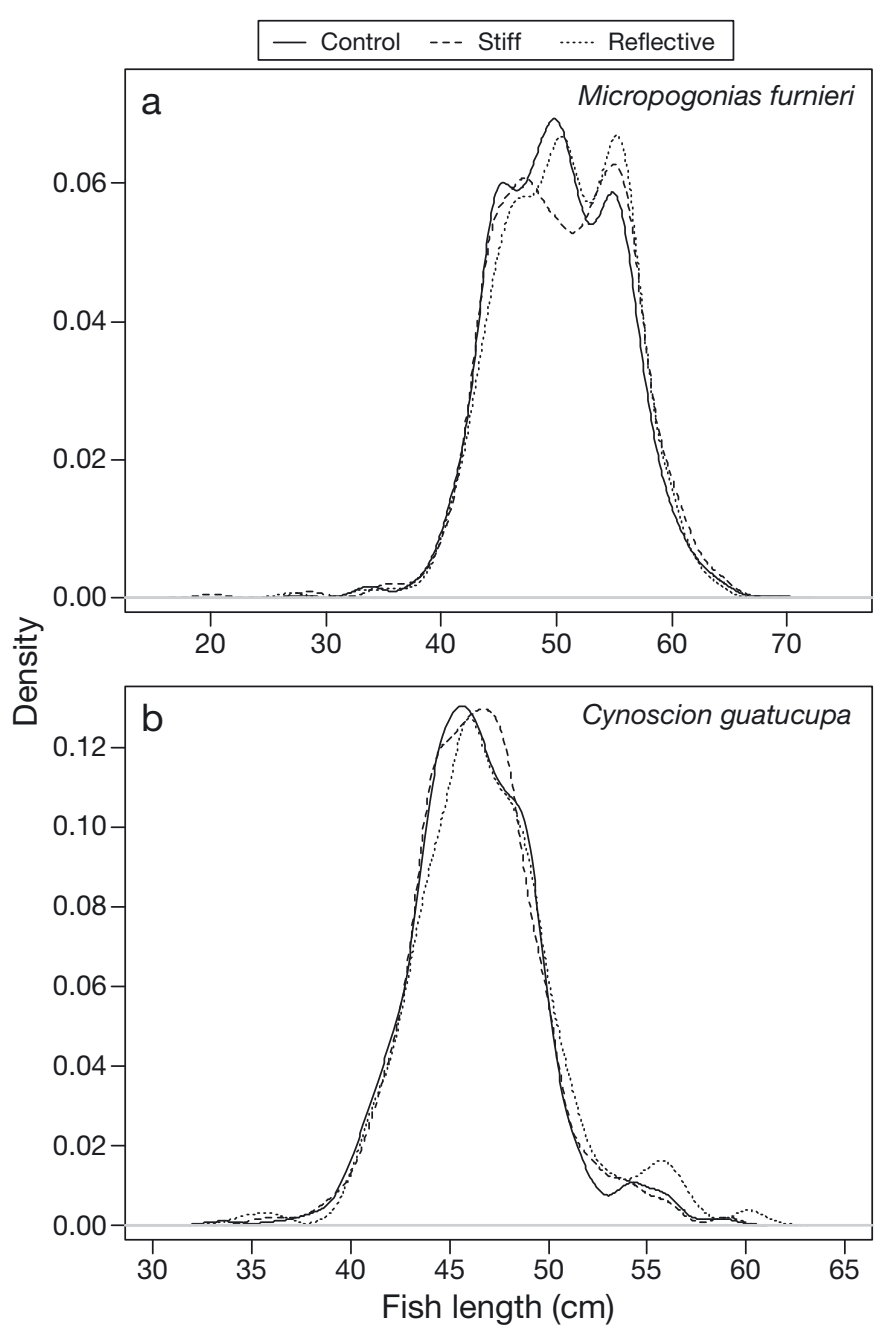

Fig. 5. Kernel density plots of (a) whitemouth croaker Micropogonias furnieri and (b) striped weakfish Cynoscion guatucupa length distributions in control, reflective and stiff nets

\section{Net behaviour}

The mean float line height for all deployments combined was $2.26 \mathrm{~m}$ for the control net $(95 \% \mathrm{CI}$ : 2.17 to 2.35 ), $2.23 \mathrm{~m}$ for the stiff net (95\% CI: 2.14 to 2.32) and $1.84 \mathrm{~m}$ for the reflective net (95\% CI: 1.77 to 1.91). Results of a GLM with Gamma error distribution and inverse link function showed that the float line height of the reflective net was significantly lower than that of the control net, but there was no significant difference in float line height between the control and stiff nets (Table 4).

In both the first and third deployments the control and stiff nets fished between 66 and $77 \%$ of the rigged net area, whilst the $\mathrm{BaSO}_{4}$ net fished between 50 and $53 \%$. During the second deployment, the stiff
Table 4. Output of the generalised linear model (with Gamma error distribution) showing the reflective net fished with a significantly lower float line height than the control net (represented by the intercept), but no significant difference between the fishing heights of the stiff and control nets

\begin{tabular}{|lrcc|}
\hline & Estimate & SE & p-value \\
\hline Intercept & 0.81 & 0.046 & $<0.001$ \\
Reflective net & -0.20 & 0.058 & $<0.001$ \\
Stiff net & -0.02 & 0.065 & $>0.05$ \\
\hline
\end{tabular}

net fished $56 \%$ of the rigged net area; the standard net, $55 \%$; and the $\mathrm{BaSO}_{4}$ net, $43 \%$. These lower estimates of fishing area for all 3 nets during the second deployment were a result of the long soak time of these nets ( $6 \mathrm{~d}$ ) as a result of bad weather, and therefore increased fish catches.

\section{DISCUSSION}

Neither reflective nor stiff gillnets produced any significant reduction in franciscana bycatch in this controlled field trial. Net type was not retained in the final GLM, and the best predictor of dolphin bycatch in the study area was location, with a positive significant relationship between bycatch rates and decreasing longitude. While not retained in the best model, as judged by AIC, highest bycatch rates occurred at depths between 11 and $15 \mathrm{~m}$. However, longitude provides a better fit to the data due to the fact that multiple entanglements were only recorded in the eastern part of the study area (Fig. 3b), therefore creating a stronger relationship between longitude and bycatch rates. Unlike the present trial, 2 previous studies reported a significant reduction in bycatch (of harbour porpoises) in gillnets with physically modified net material (Larsen et al. 2007, Trippel et al. 2009). These nets were developed based on the premise that, by increasing the acoustic reflectivity of gillnet meshes, echolocating cetaceans would be able to detect them at a sufficient distance to avoid entanglement.

Mooney et al. (2007) found acoustically reflective nets $\left(\mathrm{FeO}\right.$ and $\mathrm{BaSO}_{4}$ ) had a higher TS than standard nylon nets. However, this difference was only found at, or near, perpendicular angles to the net, and TS was found to decrease as the angle of incidence increased. The TS of the reflective nets was not tested in the current trial, but they contained the same amount of $\mathrm{BaSO}_{4}(10 \%$ by weight) as those examined by Mooney et al. (2007). Therefore, we assume they should have a higher TS than the con- 
trol nets, particularly as all the other net material properties were identical. However, this assumption may not hold, as the FS of the $\mathrm{BaSO}_{4}$ was much lower than that tested by Mooney et al. (2007), which suggests that, even with the same percentage $\mathrm{BaSO}_{4}$, the properties of the nylon were different. We cannot know how these differences may have affected the acoustic reflectivity of the reflective nets used in this trial. However, the use of reflective nets did not lead to a reduction of franciscana bycatch rates in the present study. Larsen et al. (2007) found no significant difference in TS between reflective $\mathrm{FeO}$ nets and control nets at an angle of incidence of $0^{\circ}$ and proposed that the reduction in harbour porpoise bycatch observed was most likely due to the increased stiffness of FeO nets. Trippel et al. (2009) also suggested that the increased stiffness of $\mathrm{BaSO}_{4}$ nets, as well as their increased reflectivity, contributed to the reduction in the harbour porpoise bycatch they observed. In contrast, Northridge et al. (2003) observed no reduction of harbour porpoise bycatch in $\mathrm{BaSO}_{4}$ nets.

The finding that the FS of the reflective nylon twine was significantly lower, for both wet and dry samples, than that of the control nylon twine was unexpected. The FS of the reflective net was also much lower than that reported by Mooney et al. (2007) for $\mathrm{BaSO}_{4}$ with a similar twine diameter $(\sim 0.6 \mathrm{~mm})$. In contrast, the stiff net had a higher FS than the $\mathrm{BaSO}_{4}$ net measured by Mooney et al. (2007) for dry samples (239.7 vs. 205 g, respectively), but was lower for wet samples (75.6 vs. $\sim 125 \mathrm{~g}$, respectively). Stiffness measurements of control and stiff monofilaments submerged in seawater showed an unexpected result in that the difference $(9 \%)$ was much smaller than when dry $(31 \%)$. Nevertheless, the stiff twine used in the laboratory tests had a diameter $0.025 \mathrm{~mm}$ less than that of the control monofilament sample, whereas in the field experiment the diameter of the stiff net twine came off the production line $0.05 \mathrm{~mm}$ larger than the monofilament diameter of the control net. Given the linear relationship between stiffness of monofilament and its diameter (Mooney et al. 2007), the FS of the wet control and stiff twines measured in the laboratory can be extrapolated to estimate the FS of those twines used in the field. Under a strict linear relationship the estimated FS of submerged $0.575 \mathrm{~mm}$ control twine used in the field is $63.48 \mathrm{~g}$, while the estimated FS of submerged $0.625 \mathrm{~mm}$ stiff twine used in the field is $78.75 \mathrm{~g}$. Therefore, the submerged stiff twine used in the field had an estimated increased stiffness of $19.4 \%$ relative to the submerged control twine used in the field.
The FeO nets tested by Larsen et al. (2007) were stiffer than standard nylon nets used in the trial (measured using E-alpha, the modulus of elasticity [IUPAC 1997]), but these nets were equipped with additional flotation to compensate for the increased specific gravity of the FeO mesh, so the vertical 'stiffness' of the net (its tension, rather than the material stiffness of the monofilament) would also have been greater. Additional flotation was not added to the reflective nets in this experiment or in the Trippel et al. (2009) trial. Depth sensor data collected during the present study showed that reflective nets fished with a significantly lower mean float line height than the control or stiff nets during all deployments. This reduction in the active fishing height of reflective nets did not lead to a reduction in franciscana bycatch. The number of hauls needed to have sufficient power to detect a specified reduction in bycatch rates in a net with a reduced fishing profile can be estimated using the power.of.sample function in R (Mike Lonergan, Sea Mammal Research Unit, St. Andrews). This function assumes a linear relationship between fishing profile and bycatch rates. Using the observed bycatch rate in control nets of 0.08 , this function estimated that the observed 255 hauls of both control and reflective nets are sufficient to detect a bycatch reduction of $\geq 10 \%$ in reflective nets, with a power of 0.8 , taking into account the $18 \%$ reduction in observed fishing profile of these nets. Therefore, the experimental design possessed sufficient power to conclude that the reduced fishing profile of the reflective nets did not result in a bycatch reduction of $\geq 10 \%$.

\section{Fish catches}

Fish catches, by weight, were similar in all 3 net types (Fig. 4), and there was no significant difference in CPUE for the 3 target fish species, or the 1 discard species among the control, reflective, or stiff nets ( $p>$ 0.05). Larsen et al. (2007) reported a significant reduction in CPUE (both by number and weight) of cod Gadus morhua in FeO nets, while Trippel et al. (2009) reported a significant reduction in CPUE of haddock Melanogrammus aeglefinus in $\mathrm{BaSO}_{4}$ nets. However, in the latter trial there was no significant difference in the CPUE of cod, saithe Pollachius virens, or spiny dogfish Squalus acanthias. The authors of both experiments proposed that the observed reduction of CPUE of some target species was due to the increased stiffness of the reflective nets, which could lead to a reduction in the number of enmeshed fish, as opposed to gilled fish, in the net. 
Length-frequency distributions of a sub-sample of striped weakfish and whitemouth croaker were similar between the 3 nets in the current study. Data on fish lengths were recorded from sets where the 3 net types were fished concurrently in the same location, to reduce any effect of temporal or spatial differences in fish assemblages. The significant difference found in the length distribution of whitemouth croaker between the control and stiff net was a result of a reduced number of length class $\sim 51 \mathrm{~cm}$ individuals of this species in the stiff net. Larsen et al. (2007) reported a significant reduction in the length distribution of both cod and saithe in $\mathrm{FeO}$ nets and noted that fish caught in these nets were generally gilled rather than entangled, most likely due to the increased stiffness of the FeO twine. However, due to the additional flotation on these nets, it is likely that, as well as increased twine stiffness, the nets were also stiffer in the vertical plane. Increasing the vertical stiffness of a gillnet has been shown to reduce the bycatch of some shark species, as they are less likely to become wrapped up in the webbing of the modified nets (Thorpe \& Frierson 2009). In contrast, no significant difference was found in harbour porpoise bycatch rates during a paired trial using standard skate nets and skate nets rigged with double the amount of flotation (Northridge et al. 2008). The stiff net in the present study had a higher FS than did the control net, but the underwater fishing behaviour of the 2 nets was similar. We speculate that the lower number of whitemouth croakers of length $\sim 51 \mathrm{~cm}$ caught in the stiff net may represent a point at which the increased FS of the nylon meant the mesh could no longer be deformed enough for a fish to be gilled and, furthermore, that there is a gap in length class before a larger fish can become entangled in the net.

The reduction in float line height of the reflective net did not result in a reduction of fish CPUE, but the mean length of both whitemouth croaker and striped weakfish was slightly higher than in the control or stiff net. Fish are more likely to become enmeshed, than gilled, in a slackly hung net (He 2006). It is possible that the observed reduction in the fishing profile of the reflective net resulted in greater slackness of the webbing than in the control or stiff net, and therefore in an increased probability of enmeshing larger fish. However, data on whether fish were gilled or enmeshed were not collected during the experiment, as this aspect was beyond the scope of the study.

\section{Acoustic reflectivity versus stiffness}

Neither the decreased fishing height of the reflective net, nor the relative increased stiffness of the stiff net led to a reduction in franciscana bycatch in this study. Increased reflectivity was suggested as the possible mechanism behind the reduction in harbour porpoise bycatch observed by Trippel et al. (2009), while increased stiffness was suggested as the possible mechanism behind the reduction in harbour porpoise bycatch observed by Larsen et al. (2007), but neither factor influenced franciscana bycatch rates. However, the relative difference in stiffness between the stiff and control nets, for wet samples, in the current study was much lower than the differences in stiffness between control and experimental nets reported by Larsen et al. (2007) or by Trippel et al. (2009).

Extremely limited information is available on the behaviour of franciscana; therefore, we cannot assume that the behaviour of this species, in particular their echolocation behaviour or ability to detect gillnets, is similar to that of harbour porpoises. However, a review of the current body of knowledge of the behaviour and echolocation abilities of harbour porpoises would be useful in trying to elucidate whether the acoustic properties of the reflective nets tested by Larsen et al. (2007) or Trippel et al. (2009) resulted in a decrease in harbour porpoise bycatch in these nets. Initial calculations of gillnet detection distances by harbour porpoises were based on source levels (SL) recorded for captive animals. Wild porpoises have since been recorded producing SLs up to $30 \mathrm{~dB}$ greater than those of captive animals; therefore, the estimated potential detection range of gillnets by this species was increased to around 13 to $26 \mathrm{~m}$ (Villadsgaard et al. 2007). More recently, a study has shown that free-ranging harbour porpoises detect and avoid gillnets at distances up to $80 \mathrm{~m}$ (Nielsen et al. 2012); distances at which the small increase in TS provided by acoustically reflective nets is unlikely to have much influence. Additionally, Cox \& Read (2004) found no difference in echolocation rate or echolocation intensity of harbour porpoises around $\mathrm{BaSO}_{4}$ gillnets compared to around standard gillnets, indicating that porpoises did not change their echolocation behaviour in response to the reflective net. However, Koschinski et al. (2006) found that harbour porpoises produced significantly longer inter-click-intervals (ICI) when echolocating in the vicinity of a $\mathrm{BaSO}_{4}$ gillnet than when echolocating near a standard gillnet, and concluded that this represented an increase in the range at which 
porpoises detected the $\mathrm{BaSO}_{4}$ net relative to the standard net. The work of Cox \& Read (2004) and other studies (SMRU et al. 2001, Mackay 2011) show that harbour porpoises occur near gillnets much more frequently than they become entangled, suggesting that bycatch may not result from an inability to detect nets, at least for harbour porpoises. Harbour porpoises have been found to produce a significantly higher proportion of fast click trains (ICI $<10 \mathrm{~ms}$ ) in the presence of gillnets (Mackay 2011). Harbour porpoises use fast click trains during navigation (Verfuss et al. 2005), and very fast click trains have been recorded during prey capture (DeRuiter et al. 2009, Verfuss et al. 2009). The increased use of such trains in the vicinity of gillnets show that free-ranging harbour porpoises were either acoustically investigating prey around gillnets - or the gillnets themselves at relatively close distances without becoming entangled. Therefore, the current body of knowledge suggests that the relatively small increase in TS recorded for reflective nets, and limited angles of incidence at which this difference occurs, is unlikely to affect the distance at which harbour porpoises can detect gillnets. In addition, an object with a higher TS, such as a herring, could easily negate the small increase in acoustic reflectivity of such nets relative to standard nylon nets (Mooney et al. 2007). Indeed, $\mathrm{BaSO}_{4}$ nets had a higher porpoise bycatch rate per string than control nets (0.07 vs. 0.04) in 1 mo during the study by Trippel et al. (2009). The authors concluded that this increased bycatch was likely due to an increase in herring in the area and a concurrent increase in harbour porpoise densities. While there is no information on the SL of echolocation clicks produced by franciscana, or their behaviour around gillnets, the information above suggests that the reduction in bycatch rates in reflective nets reported by Trippel et al. (2009) was unlikely to be caused by the acoustic properties of these nets. In contrast, the results of the depth sensor data in the current experiment may provide a more parsimonious explanation of the decrease in harbour porpoise bycatch in $\mathrm{BaSO}_{4}$ nets observed by Trippel et al. (2009).

Float line height has been shown to decrease as current speed increases (Stewart 1988). Results from the current study showed an $18 \%$ decrease in the fishing profile of the reflective nets relative to the control and stiff nets. Current speeds in the study area in Argentina reach up to $0.29 \mathrm{~m} \mathrm{~s}^{-1}$ (Framinan et al. 2008). In contrast, current speeds in the Bay of Fundy can reach $0.64 \mathrm{~m} \mathrm{~s}^{-1}$ (Brillant \& Trippel 2009). Cox \& Read (2004) reported significantly higher CPUE of American lobster Homerus americanus in
$\mathrm{BaSO}_{4}$ nets compared to control nets, and suggested that given the heavier weight of the modified net webbing, the $\mathrm{BaSO}_{4}$ nets may have been lying on the seafloor for longer periods than the control nets. This observation, along with the data from the depth sensor trial in the current study, suggests that at least some of the observed reduction in harbour porpoise bycatch rates reported by Trippel et al. (2009) may have been a result of a decrease in fishing height, and therefore fishing area, of $\mathrm{BaSO}_{4}$ nets. Given the greater current speeds in their study area, this decrease in fishing profile is likely to have been greater than the $18 \%$ reduction observed in the present study.

\section{Other factors}

The twine of all 3 net types used in the current trial was dyed yellow to blend in with the muddy water colour in the study area. The twine of the $\mathrm{BaSO}_{4}$ nets used by Trippel et al. (2009) was pale blue, whilst the control nets had transparent twine, and the twine of the FeO nets used by Larsen et al. (2007) was reddishbrown compared to the silvery-green of the control nets. Both research groups noted that differences in colour could not be excluded as having contributed to the observed reductions in harbour porpoise bycatch rates. However, as most fishing in the Larsen et al. (2007) study was conducted at night, and at depths with low light levels, the authors suggested that twine colour was unlikely to be the main factor behind the observed reduction in bycatch rates. In a previous report of results of their $\mathrm{BaSO}_{4}$ trial Trippel et al. (2003) also reported a significant decrease in seabird bycatch in the reflective nets, and concluded that this reduction was likely due to the opaque colour of the $\mathrm{BaSO}_{4}$ nets. In light of the net behaviour results obtained in the current trial, it is also possible that this reduction was a result of reflective nets fishing with a reduced height compared to standard nets.

\section{CONCLUSIONS}

Bycatch rates of franciscana were not reduced in reflective nets, suggesting that this gear modification is not an effective mitigation strategy for this species. This could, in part, be due to the echolocation behaviour of this species. franciscana produce narrowband, high-frequency echolocation clicks between 130 to $149 \mathrm{kHz}$ (Melcón et al. 2012); however, to date, the source level of these clicks has not been re- 
corded. Although it appears that this species has the ability to detect gillnets, evidence to date suggests they do not echolocate frequently (Melcón et al. 2012). The increased TS of $\mathrm{BaSO}_{4}$ nets tested by Trippel et al. (2009) has been proposed as the mechanism which led to the decreased harbour porpoise bycatch rates they observed. However, the current body of knowledge on the behaviour of harbour porpoises around gillnets shows that this species can detect gillnets at distances greater than those given by relatively small increases in the TS of $\mathrm{BaSO}_{4}$ nets, suggesting that this is not the mechanism by which harbour porpoise bycatch was reduced in the trial by Trippel et al. (2009). Additionally, increasing the acoustic reflectivity of gillnets would not provide a universal mitigation strategy for bycatch of nonecholocating marine mammals or other marine mega-fauna.

Mooney et al. (2007) reported a $\mathrm{FS}$ of $\mathrm{BaSO}_{4}$ twine $33 \%$ higher than standard nylon twine of an identical diameter, while the difference in FS between $\mathrm{FeO}$ and standard nylon reported by Larsen et al. (2009), although measured differently, was $234 \%$. The increased FS of submerged stiff net monofilament, calculated in this experiment to be $19.4 \%$ higher than that of the control twine, did not result in a reduction in franciscana bycatch rates. Likewise, the $18 \%$ reduction in the fishing profile of the reflective net did not lead to a reduction in franciscana bycatch rates.

Acknowledgements. Our deep gratitude goes to the local artisanal fishermen from the UAPA (Argentina Artisanal Fishermen Federal Union), whose continued cooperation made this, and previous studies, possible. We also thank the observers from Aquamarina, for their diligent work in the field, and Kate McClellan, New England Aqaurium, for laboratory assistance. Mike Lonergan provided valuable comments and statistical discussions. The study was funded by the Lenfest Ocean Program. Additional logistic support was provided by Fundacion Vida Silvestre, Argentina, and ProWildlife, Germany. A.I.M was supported by a NERC studentship.

\section{LITERATURE CITED}

Anderson ORJ, Small CJ, Croxall JP, Dunn EK, Sullivan BJ, Yates O, Black A (2011) Global seabird bycatch in longline fisheries. Endang Species Res 14:91-106

Bordino P, Albareda D (2004) Incidental mortality of Franciscana dolphin Pontoporia blainvillei in coastal gillnet fisheries in northern Buenos Aires, Argentina. IWCSC/56/ SM11, IWC Scientific Committee. Paper presented to the IWC Scientific Committee, July 2004, Sorrento, Italy. www.iwcoffice.org

Bordino P, Kraus S, Albareda D, Fazio A, Palmerio A, Mendez M, Botta S (2002) Reducing incidental mortality of Franciscana dolphin Pontoporia blainvillei with acoustic warning devices attached to fishing nets. Mar Mamm Sci 18:833-842

Brillant SW, Trippel EA (2009) Elevations of lobster fishery groundlines in relation to their potential to entangle endangered North Atlantic right whales in the Bay of Fundy, Canada. ICES J Mar Sci 67:355-364

Campbell R, Holley D, Christianopoulos D, Caputi N, Gales N (2008) Mitigation of incidental mortality of Australian sea lions in the west coast rock lobster fishery. Endang Species Res 5:345-358

> Carretta JV, Barlow J (2011) Long-term effectiveness, failure rates, and 'dinner bell' properties of acoustic pingers in a gillnet fishery. Mar Technol Soc J 45:7-19

Carretta JV, Barlow J, Enriquez L (2008) Acoustic pingers eliminate beaked whale bycatch in a gill net fishery. Mar Mamm Sci 24:956-961

Corcueara J, Monzon F, Crespo EA, Aguilar A, Raga JA (1994) Interactions between marine mammals and the coastal fisheries of Necochea and Claromeco (Buenos Aires Province, Argentina). Rep Int Whal Comm 15(Spec Issue):283-290

Cox TM, Read AJ (2004) Echolocation behavior of harbor porpoises Phocoena phocoena around chemically enhanced gill nets. Mar Ecol Prog Ser 279:275-282

Crespo EA, Pedraza SN, Grandi MF, Dans SL, Garaffo GV (2010) Abundance and distribution of endangered Franciscana dolphins in Argentine waters and conservation implications. Mar Mamm Sci 26:17-35

Dawson S (1994) The potential for reducing entanglement of dolphins and porpoises with acoustic modifications to gillnets. Rep Int Whal Comm 15(Spec Issue):573-578

> Dawson SM, Northridge S, Waples D, Read AJ (2013) To ping or not to ping: the use of active acoustic devices in mitigating interactions between small cetaceans and gillnet fisheries. Endang Species Res 19:201-221

DeRuiter, SL, Bahr A, Blanchet M, Hansen SF and others (2009) Acoustic behaviour of echolocating porpoises during prey capture. J Exp Biol 212:3100-3107

Framinan MB, Valle-Levinson A, Sepulveda HH, Brown OB (2008) Tidal variation of flow convergence, shear, and stratification at the Rio de la Plata estuary turbidity front. J Geophys Res 113:1-17

Gardner B, Sullivan PJ, Morreale SJ, Epperly SP (2008) Spatial and temporal statistical analysis of bycatch data: patterns of sea turtle bycatch in the North Atlantic. Can J Fish Aquat Sci 65:2461-2470

Gilman E, Gearhart J, Price B, Eckert S and others (2010) Mitigating sea turtle by-catch in coastal passive net fisheries. Fish Fish 11(1):57-88

> Goldsworthy SD, Page B (2007) A risk-assessment approach to evaluating the significance of seal bycatch in two Australian fisheries. Biol Conserv 139:269-285

He PG (2006) Gillnets: gear design, fishing performance and conservation challenges. Mar Technol Soc J 40:12-19

IUPAC (International Union of Pure and Applied Chemistry) (1997) Compendium of chemical terminology, 2nd edn. McNaught AD, Wilkinson A (compilers). Blackwell Scientific Publications, Oxford

Kasuya T, Brownell RL (1979) Age determination, reproduction and growth of franciscana dolphin Pontoporia blainvillei. Sci Rep Whale Res Inst 31:45-67

> Koschinski S, Culik BM, Trippel EA, Ginzkey L (2006) Behavioral reactions of free-ranging harbor porpoises Phocoena phocoena encountering standard nylon and 
$\mathrm{BaSO}_{4}$ mesh gillnets and warning sound. Mar Ecol Prog Ser 313:285-294

Kraus SD, Read AJ, Solow A, Baldwin K, Spradlin T, Anderson E, Williamson J (1997) Acoustic alarms reduce porpoise mortality. Nature 388:525-526

Larsen F, Eigaard OR, Tougaard J (2002) Reduction of harbour porpoise by-catch in the North Sea by high-density gill nets. IWC/SC/54/SM30, IWC Scientific Committee. Paper presented to the IWC Scientific Committee, April 2002, Shimonoseki, Japan. www.iwcoffice.org

Larsen F, Eigaard OR, Tougaard J (2007) Reduction of harbour porpoise Phocoena phocoena bycatch by iron-oxide gillnets. Fish Res 85:270-278

Mackay AI (2011) An investigation of factors related to the bycatch of small cetaceans in fishing gear. PhD dissertation, University of St Andrews, St Andrews

Melcón ML, Failla M, Iñíguez MA (2012) Echolocation behavior of franciscana dolphins (Pontoporia blainvillei) in the wild. J Acoust Soc Am 131:EL448-EL453

> Minami M, Lennert-Cody CE, Gao W, Roman-Verdesoto M (2007) Modelling shark bycatch: the zero-inflated negative binomial regression model with smoothing. Fish Res 84:210-221

Mooney TA, Nachtigall PE, Au DW (2004) Target strength of a nylon monofilament and an acoustically enhanced gillnet: predictions of biosonar detection ranges. Aquat Mamm 30:220-226

> Mooney TA, Au WWL, Nachtigall PE, Trippel EA (2007) Acoustic and stiffness properties of gillnets as they relate to small cetacean bycatch. ICES J Mar Sci 64: 1324-1332

Murray KT, Read AJ, Solow AR (2000) The use of time/area closures to reduce bycatches of harbour poporises: lessons from the Gulf of Maine sink gillnet fishery. J Cetacean Res Manag 2:135-141

Nielsen TP, Wahlberg M, Heikkila S, Jensen M, Sabinsky P, Dabelsteen T (2012) Swimming patterns of wild harbour porpoises Phocoena phocoena show detection and avoidance of gillnets at very long ranges. Mar Ecol Prog Ser 453:241-248

Northridge S, Sanderson D, Mackay A, Hammond P (2003) Analysis and mitigation of cetacean bycatch in UK fisheries: final report to DEFRA Project MF0726. Sea Mammal Research Unit, St. Andrews

Northridge S, Kingston A, Murphy S, Mackay A (2008) Monitoring, impact and assessment of marine mammal bycatch: final report to DEFRA Project MF0736. Sea Mammal Research Unit, St. Andrews

Orphanides CD (2009) Protected species bycatch estimating approaches: estimating harbor porpoise bycatch in U.S. northwestern Atlantic gillnet fisheries. J Northwest Atl Fish Sci 42:55-76

Palka DL, Rossman MC, VanAtten AS, Orphanides CD (2008) Effect of pingers on harbour porpoise bycatch in the US northeast gillnet fishery. J Cetacean Res Manag 10:217-226

Praderi R, Pinedo MC, Crespo E (1989) Conservation and management of Pontoporia blainvillei in Uruguay, Brazil and Argentina. In: Perrin WE, Brownell RL, Zhou K, Liu J (eds) Biology and conservation of the river dolphins. Occ Pap IUCN SSC 3:52-56

Editorial responsibility: Randall Reeves,

Hudson, Quebec, Canada
Read AJ (2008) The looming crisis: interactions between marine mammals and fisheries. J Mammal 89:541-548

Read AJ, Drinker P, Northridge S (2006) Bycatch of marine mammals in US and global fisheries. Conserv Biol 20: 163-169

Reeves RR, Dalebout ML, Jefferson TA, Karczmarski L and others (2008). Pontoporia blainvillei. In: IUCN 2012. IUCN Red List of Threatened Species, Version 2012.1. Available at: www.iucnredlist.org (accessed 19 June 2012)

Secchi ER (2010) Review on the threats and conservation status of Franciscana, Pontoporia blainvillei (Cetacea, Pontoporiidae). In: Shostell JM, Ruiz-Garcia M (eds) Biology, evolution and conservation of river dolphins within South America and Asia, Vol 1. Nova Science Publishers Inc., Hauppauge, p 323-339

Secchi E, Ott PH, Danilewicz D (2003) Effects of fishing bycatch and the conservation status of the franciscana dolphin, Pontoporia blainvillei. In: Gales NJ, Hindell MA, Kirkwood R, Andrew M (eds) Marine mammals: fisheries, tourism and management issues. CSIRO Publishing, Melbourne

Sims M, Cox T, Lewison R (2008) Modelling spatial patterns in fisheries bycatch: improving bycatch maps to aid fisheries management. Ecol Appl 18:649-661

Slooten E (2013) Effectiveness of area-based management in reducing bycatch of the New Zealand dolphin. Endang Species Res 20:121-130

SMRU (Sea Mammal Research Unit), UCC, CFPO, ISWFO (2001) Reduction of porpoise bycatch in bottom set gillnet fisheries. Report to the European Commission, DG Fisheries. Study Contract 97/095, SMRU, St. Andrews

Stewart PAM (1988) Measurements of the effects of tidal flow on the headline heights of bottom-set gillnets. Fish Res 6:181-189

> Thorpe T, Frierson D (2009) Bycatch mitigation assessment for sharks caught in coastal anchored gillnets. Fish Res 98:102-112

> Trippel EA, Holy NL, Palka DL, Shepherd TD, Melvin GD, Terhune JM (2003) Nylon barium sulphate gillnet reduces porpoise and seabird mortality. Mar Mamm Sci 19:240-243

Trippel EA, Holy NL, Shepherd TD (2009) Barium sulphate modified fishing gear as a mitigative measure for cetacean incidental mortalities. J Cetacean Res Manag 10:235-246

Verfuss UK, Miller LA, Schnitzler HU (2005) Spatial orientation in echolocating harbour porpoises Phocoena phocoena. J Exp Biol 208:3385-3394

Verfuss UK, Miller LA, Pilz PKD, Schnitzler HU (2009) Echolocation by two foraging harbour porpoises (Phocoena phocoena). J Exp Biol 212:823-834

Villadsgaard A, Wahlberg M, Tougaard J (2007) Echolocation signals of wild harbour porpoises, Phocoena phocoena. J Exp Biol 210:56-64

Vinther M, Larsen F (2004) Updated estimates of harbour porpoise Phocoena phocoena bycatch in the Danish North Sea bottom-set gillnet fishery. J Cetacean Res Manag 6:19-24

Watson JW, Epperly SP, Shah AK, Foster DG (2005) Fishing methods to reduce sea turtle mortality associated with pelagic longlines. Can J Fish Aquat Sci 62:965-981

Submitted: June 13, 2012; Accepted: February 8, 2013

Proofs received from author(s): May 22, 2013 